\title{
Nanotwins soften boron-rich boron carbide $\left(B_{13} C_{2}\right)$
}

Qi An and William A. GoddardIII

Citation: Appl. Phys. Lett. 110, 111902 (2017); doi: 10.1063/1.4978644

View online: http://dx.doi.org/10.1063/1.4978644

View Table of Contents: http://aip.scitation.org/toc/apl/110/11

Published by the American Institute of Physics

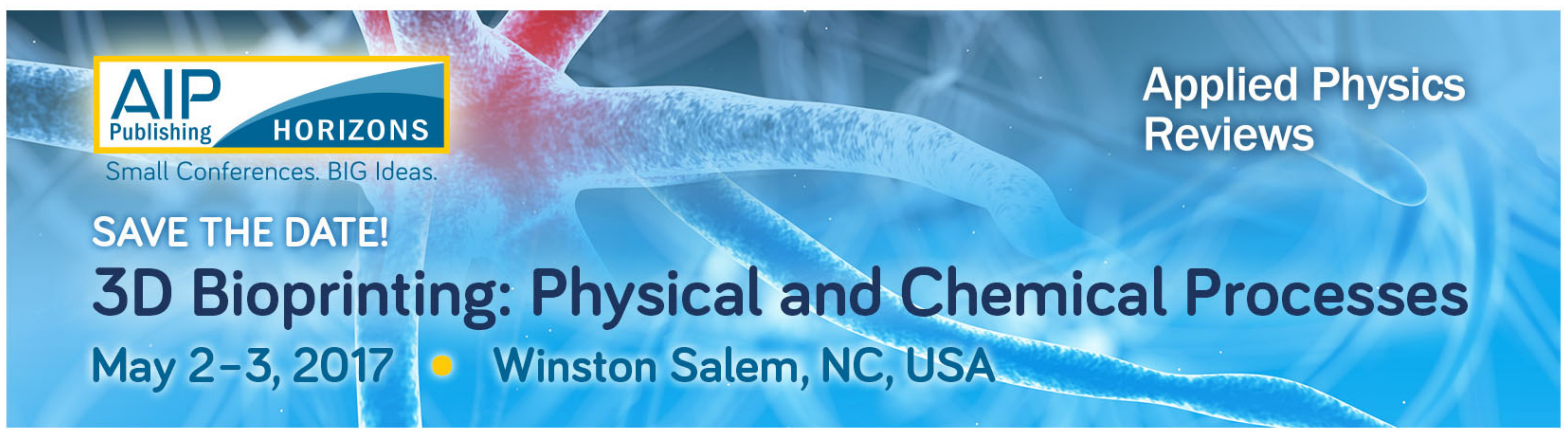




\title{
Nanotwins soften boron-rich boron carbide $\left(B_{13} C_{2}\right)$
}

\author{
Qi $\mathrm{An}^{1,2,3}$ and William A. Goddard III, a) \\ ${ }^{1}$ Materials and Process Simulation Center, California Institute of Technology, Pasadena, California 91125 , \\ USA \\ ${ }^{2}$ Department of Chemical and Materials Engineering, University of Nevada, Reno, Reno, Nevada 89557, USA \\ ${ }^{3}$ Nevada Institute for Sustainability, University of Nevada, Reno, Reno, Nevada 89557, USA
}

(Received 26 November 2016; accepted 26 February 2017; published online 16 March 2017)

Extensive studies of metals and alloys have observed that nanotwins lead to strengthening, but the role of nanotwins in ceramics is not well established. We compare here the shear strength and the deformation mechanism of nanotwinned boron-rich boron carbide $\left(\mathrm{B}_{13} \mathrm{C}_{2}\right)$ with the perfect crystal under both pure shear and biaxial shear deformations. We find that the intrinsic shear strength of crystalline $B_{13} C_{2}$ is higher than that of crystalline boron carbide $\left(B_{4} C\right)$. But nanotwins in $B_{13} C_{2}$ lower the strength, making it softer than crystalline $\mathrm{B}_{4} \mathrm{C}$. This reduction in strength of nanotwinned $\mathrm{B}_{13} \mathrm{C}_{2}$ arises from the interaction of the twin boundary with the C-B-C chains that connect the $\mathrm{B}_{12}$ icosahedra. Published by AIP Publishing. [http://dx.doi.org/10.1063/1.4978644]

Boron carbide $\left(\mathrm{B}_{4} \mathrm{C}\right)$ is of great interest because of its promising properties of low density, superhardness, thermal stability, and high elastic Hugoniot limit. ${ }^{1-5}$ However, engineering applications of $\mathrm{B}_{4} \mathrm{C}$ to body armor or abrasive powders have been impeded by the high pressure brittle failure due to amorphous shear band formation. ${ }^{6-8}$ We recently used atomistic simulations to show that amorphous shear band underlying the brittle failure in $\mathrm{B}_{4} \mathrm{C}$ arises from fracture of the $\mathrm{B}_{11} \mathrm{C}$ icosahedra which increases the density of the amorphous band compared to nearby crystalline regions, leading to tension that induces cavitation and then failure. ${ }^{9}$ Under realistic conditions, defects such as twinning and grain boundaries might play important roles in determining the mechanical properties and failure mechanism of $\mathrm{B}_{4} \mathrm{C}$ and related materials. ${ }^{10,11}$ In particular, the ubiquitous existence of twins in these materials has motived studies of their impact. ${ }^{12-15}$ Indeed, we recently used both theory and experiment to examine the twin structures in $\mathrm{B}_{4} \mathrm{C}$ and boron-rich boron carbide $\left(\mathrm{B}_{13} \mathrm{C}_{2}\right) .{ }^{14}$ In addition, the nanotwins in $\mathrm{B}_{4} \mathrm{C}$ could strengthen the materials by suppression of twin boundary (TB) slip within the nanotwins. ${ }^{15}$ However, the mechanism by which these nanotwinned structures determine mechanical properties is not fully understood at the atomistic scale, especially for $\mathrm{B}_{13} \mathrm{C}_{2}$. Although some experimental observed planar defects in $\mathrm{B}_{13} \mathrm{C}_{2}$ may be Wadsley type defects such as stacking faults, we do not consider them in current study because the atomistic structures for these defects are not identified.

Boron carbide exhibits a wide range of carbon solid solubilities ranging from $\sim 8$ to $\sim 20$ at. $\%$. In particular, it is of interest to understand how the properties of $\mathrm{B}_{13} \mathrm{C}_{2}$ are compared to $\mathrm{B}_{4} \mathrm{C}$. To explain the stoichiometry of $\mathrm{B}_{13} \mathrm{C}_{2}$, structures such as $\mathrm{B}_{12}(\mathrm{BBC}), \mathrm{B}_{12}(\mathrm{CBC})$, and $\mathrm{B}_{12}(\mathrm{BBBB})$ have been proposed. ${ }^{16-18}$ Previous $\mathrm{QM}$ simulations predicted that the $\mathrm{B}_{12}(\mathrm{CBC})$ is the lowest energy structure among all the possible variations of the basic $\mathrm{B}_{4} \mathrm{C}$ structure. ${ }^{19}$ Indeed, the experimental Raman spectrum is consistent with the

\footnotetext{
${ }^{\text {a) }}$ Author to whom correspondence should be addressed. Electronic mail: wag@wag.caltech.edu
}

$\mathrm{B}_{12}(\mathrm{CBC})$ predicted structure, ${ }^{20}$ indicating this to be the most plausible structure for B-rich boron carbide. Note that in discussing experiments we use the terms $\mathrm{B}_{13} \mathrm{C}_{2}$ and $\mathrm{B}_{4} \mathrm{C}$, whereas for the computations we use notations such as $\mathrm{B}_{12}(\mathrm{CBC})$. This is because the experimentalists know for sure the overall compositions, but do not know which atoms are in the icosahedra and chains, whereas for the theory we use the specific distributions that correspond to the lowest energy.

We report here quantum mechanics $(\mathrm{QM})$ simulations for the deformations of both perfect and twinned $\left(\mathrm{B}_{12}\right) \mathrm{CBC}$, which we compare with $\left(\mathrm{B}_{11} \mathrm{C}_{\mathrm{p}}\right) \mathrm{CBC}$. We find that the shear strength of perfect $\left(\mathrm{B}_{12}\right) \mathrm{CBC}$ is $17.7 \%$ higher than that of $\left(B_{11} C_{p}\right) C B C$ under pure shear deformations, while they are similar (within 0.4\%) under indentation conditions. However, the presence of twins decreases the shear strength of perfect $\left(\mathrm{B}_{12}\right) \mathrm{CBC}$ under both conditions, making it even softer than $\left(B_{11} C_{p}\right) C B C$. We find that the failure mechanism of twinned $\left(B_{12}\right) C B C$ arises from the interaction of the C-B-C chain with the high energy twin boundary (TB). This allows the stress to achieve sufficient strain to cause deconstruction of the $\left(\mathrm{B}_{12}\right)$ icosahedral cluster to be $21.6 \%$ smaller than for perfect $\left(\mathrm{B}_{12}\right) \mathrm{CBC}$.

Our QM simulations use the Perdew-Burke-Ernzerhof (PBE) exchange-correlation functional with the projector augmented wave method for the core-valence interactions as implemented in the VASP package. ${ }^{21-24}$ We found that a kinetic energy cutoff of $500 \mathrm{eV}$ for the plane wave expansions gives excellent convergence of the total energies, energy differences, and structural parameters. The convergence criteria were set to $1 \times 10^{-6} \mathrm{eV}$ energy difference for solving the electronic wave function and $1 \times 10^{-3} \mathrm{eV} / \AA$ force for geometry optimization. Reciprocal space was sampled using the $\Gamma$-centered Monkhorst-Pack scheme with a fine resolution less than $2 \pi \times 1 / 60 \AA^{-1}$ for geometry optimization.

We applied the pure shear deformation by fixing the shear strain at various values while relaxing the other five strain components. ${ }^{25}$ To mimic the stress conditions under indentation experiments, we applied biaxial shear deformation where the ratio of the compressive stress beneath the indenter normal to the chosen shear plane has a fixed fraction 
of the tangential stress while the other four strain components are relaxed. ${ }^{26}$ Here, we set the centerline-to-face angle to $68^{\circ}$ to mimic the Vickers indenter. The residual stresses after relaxing were less than $0.5 \mathrm{GPa}$ for pure shear and biaxial shear deformation.

Fig. 1(a) displays the $\mathrm{B}_{12}(\mathrm{CBC})$ crystal structure with $\mathrm{R} \overline{3} \mathrm{~m}$ space group where the $\mathrm{B}_{12}$ icosahedral cluster is located on the corner and the C-B-C chain is along the $[111]_{\mathrm{r}}$ directions. Here, the subscript " $r$ " represents the rhombohedral cell. To examine how the twinned structure changes the mechanical properties of the perfect $\mathrm{B}_{12}(\mathrm{CBC})$, we constructed the twinned structure with the twin boundary along the $\{100\}_{\mathrm{r}}$ plane as shown in Fig. 1(b). Details of this twinned structure were discussed previously. ${ }^{15}$ The QM predicts a twin interfacial energy of $40.6 \mathrm{~mJ} / \mathrm{m}^{2}$ for $\mathrm{B}_{12}(\mathrm{CBC})$, which is much lower than the $83.2 \mathrm{~mJ} / \mathrm{m}^{2}$ for symmetric $\mathrm{B}_{11} \mathrm{C}_{\mathrm{p}}(\mathrm{CBC}) .{ }^{15}$ This much lower interfacial energy for $\mathrm{B}_{12}(\mathrm{CBC})$ might arise from the easier accommodation of $\mathrm{B}_{12}$ icosahedra along the twin boundary compared with $\mathrm{B}_{11} \mathrm{C}$ icosahedra. This low TB energy might explain why twin planar defects are pervasive in $\mathrm{B}_{13} \mathrm{C}_{2}$, whereas it is possible to form twin-free grains in $\mathrm{B}_{4} \mathrm{C}$ that are micrometers across. ${ }^{15}$

Our previous studies showed that the easiest shear slip system for $\mathrm{B}_{4} \mathrm{C}$ is $(001)_{\mathrm{r}} /<001>_{\mathrm{r}}$ which parallels the amorphous shear band observed in experiments. ${ }^{6-8}$ For $\mathrm{B}_{12}(\mathrm{CBC})$, we performed pure shear deformation along the same slip system. For the twinned $\mathrm{B}_{12}(\mathrm{CBC})$, we shear along the TB which is along the $\{001\}_{\mathrm{r}}$ plane of perfect $\mathrm{B}_{12}(\mathrm{CBC})$. The stress-strain relationships for these two structures are displayed in Fig. 2, and compared with the perfect $\mathrm{B}_{11} \mathrm{C}_{\mathrm{p}}(\mathrm{CBC})$ crystal examined previously. ${ }^{8}$ The maximum shear stress for perfect $\mathrm{B}_{12}(\mathrm{CBC})$ is $45.8 \mathrm{GPa}$, which is $17.7 \%$ higher than the strength limit of $\mathrm{B}_{4} \mathrm{C}(38.9 \mathrm{GPa})$, indicating that the intrinsic strength limit is higher for perfect $\mathrm{B}_{12}(\mathrm{CBC})$ than for $\mathrm{B}_{11} \mathrm{C}_{\mathrm{p}}(\mathrm{CBC})$. However, the shear strength of twinned $\mathrm{B}_{12}(\mathrm{CBC})$ decreases to $35.9 \mathrm{GPa}$, which is $21.6 \%$ lower than that of perfect $\mathrm{B}_{12}(\mathrm{CBC})$ and $7.7 \%$ lower than that of perfect $\mathrm{B}_{4} \mathrm{C}$. The critical shear stress for $\mathrm{B}_{12}(\mathrm{CBC})$ and $\mathrm{B}_{11} \mathrm{C}_{\mathrm{p}}(\mathrm{CBC})$ is summarized in Table $\mathrm{I}$. The $\mathrm{B}_{12}(\mathrm{CBC})$ directly fails after the maximum shear stress as shown in Fig. 2, indicating that it does not experience any "plastic" deformation. In contrast, $\mathrm{B}_{11} \mathrm{C}_{\mathrm{p}}(\mathrm{CBC})$ does exhibit
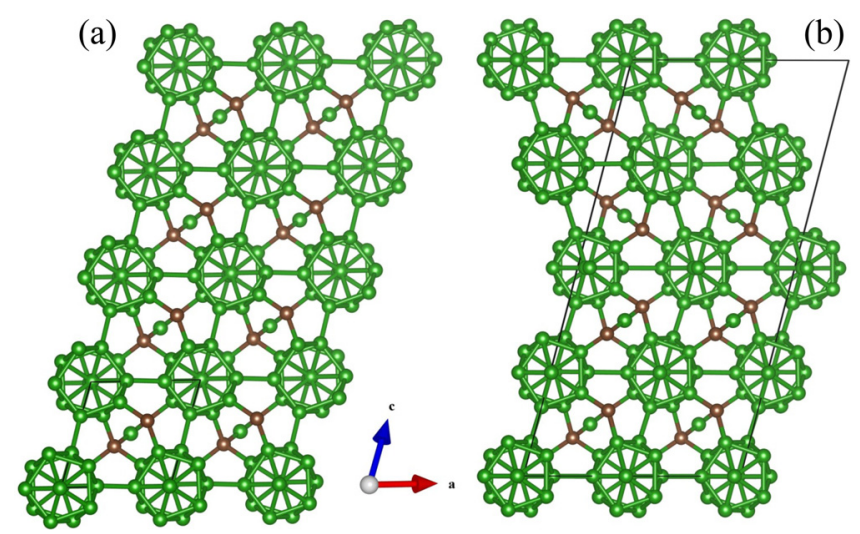

FIG. 1. The structure of $\mathrm{B}_{12}(\mathrm{CBC})$ and its twin structure from $\mathrm{QM}$ prediction: (a) $\mathrm{QM}$ predicted structure for $\mathrm{B}_{12}(\mathrm{CBC})$. (b) QM predicted structure for twinned $\mathrm{B}_{12}(\mathrm{CBC})$ with 2 crystal layers between twin boundaries. The boron and carbon atoms are represented by green and cyan balls, respectively.

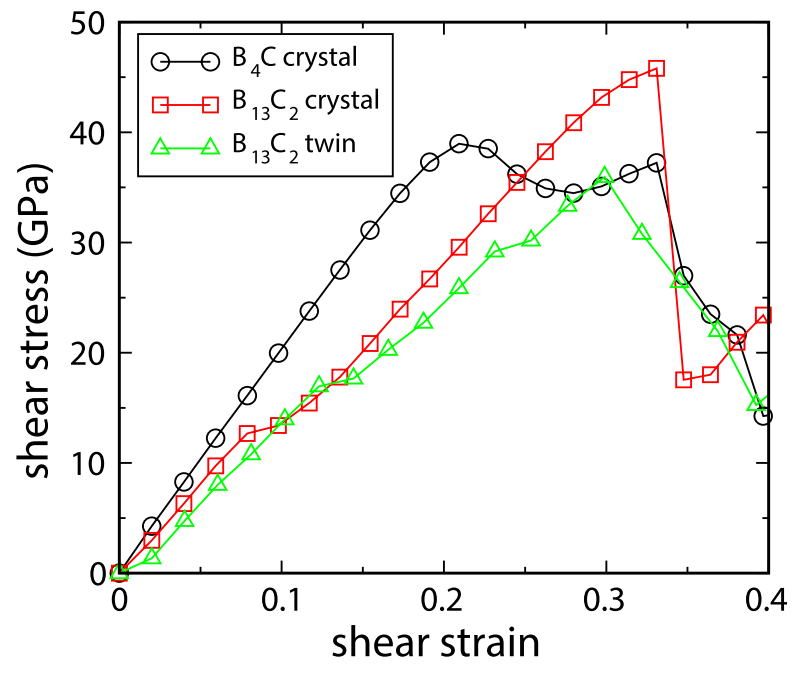

FIG. 2. The shear-stress shear-strain relationship of $\mathrm{B}_{12}(\mathrm{CBC})$, twinned $\mathrm{B}_{12}(\mathrm{CBC})$, and $\mathrm{B}_{11} \mathrm{C}_{\mathrm{p}}(\mathrm{CBC})$ along the least stress slip system.

"plasticity," of $12.1 \%$, in the infinite slow shear deformation at $0 \mathrm{~K}$ along the most plausible slip system $(001)_{\mathrm{r}} /\langle 001\rangle_{\mathrm{r}}$, as shown in Fig. 2.

To understand the softening effect from nanotwins in $\mathrm{B}_{12}(\mathrm{CBC})$ and to illustrate amorphous band formation at high strain, we examined the structural changes in perfect and twinned $\mathrm{B}_{12}(\mathrm{CBC})$, as shown in Fig. 3. For perfect $\mathrm{B}_{12}(\mathrm{CBC})$, the structure deforms continuously as the strain increases to 0.331 without bending the $\mathrm{C}-\mathrm{B}-\mathrm{C}$ chain, as shown in Fig. 3(a). But with a strain of 0.348 , we find that $\mathrm{B}_{12}(\mathrm{CBC})$ fails catastrophically, as shown in Fig. 3(b). This differs from the failure mechanism of $B_{4} C$, which involves a two-step procedure: ${ }^{8}$

(1) the B-C bond between icosahedra is stretched and broken to form a reactive carbene;

(2) the system then displays plastic deformation for an additional 0.122 strain until at 0.331 , in which the C-B-C chain has bent sufficiently for the carbene to react with the middle $\mathrm{B}$ of the chain, resulting in deconstruction of icosahedron with concomitant formation of the amorphous band. The first step at 0.209 strain for $\mathrm{B}_{11} \mathrm{C}_{\mathrm{p}}(\mathrm{CBC})$ releases the stress, decreasing the maximum shear strength below than that for the perfect $\mathrm{B}_{12}(\mathrm{CBC})$.

For twinned $\mathrm{B}_{12}(\mathrm{CBC})$, the stress-strain slope is $4.4 \%$ lower than for perfect $\mathrm{B}_{12}(\mathrm{CBC})$, indicating a lower shear modulus, which arises from the presence of the high energy TBs. As shear stress is applied to the twinned $\mathrm{B}_{12}(\mathrm{CBC})$, the C-B-C chains in the lower half start to bend towards the icosahedral clusters along the TBs before failure, as shown in

TABLE I. Critical shear stress for $\mathrm{B}_{11} \mathrm{C}_{\mathrm{p}}(\mathrm{CBC})$ and $\mathrm{B}_{12}(\mathrm{CBC})$ under pure and biaxial shear deformation. The data for symmetric twinned $\mathrm{B}_{11} \mathrm{C}_{\mathrm{p}}(\mathrm{CBC})$ are from Ref. 15.

\begin{tabular}{lcc}
\hline \hline Critical shear Stress $(\mathrm{GPa})$ & $\mathrm{B}_{11} \mathrm{C}_{\mathrm{p}}(\mathrm{CBC})$ & $\mathrm{B}_{12}(\mathrm{CBC})$ \\
\hline Perfect (pure shear) & 38.9 & 45.8 \\
Twin (pure shear) & 43.6 & 35.9 \\
Perfect (biaxial shear) & 28.5 & 28.6 \\
Twin (biaxial shear) & 31.8 & 26.0 \\
\hline \hline
\end{tabular}




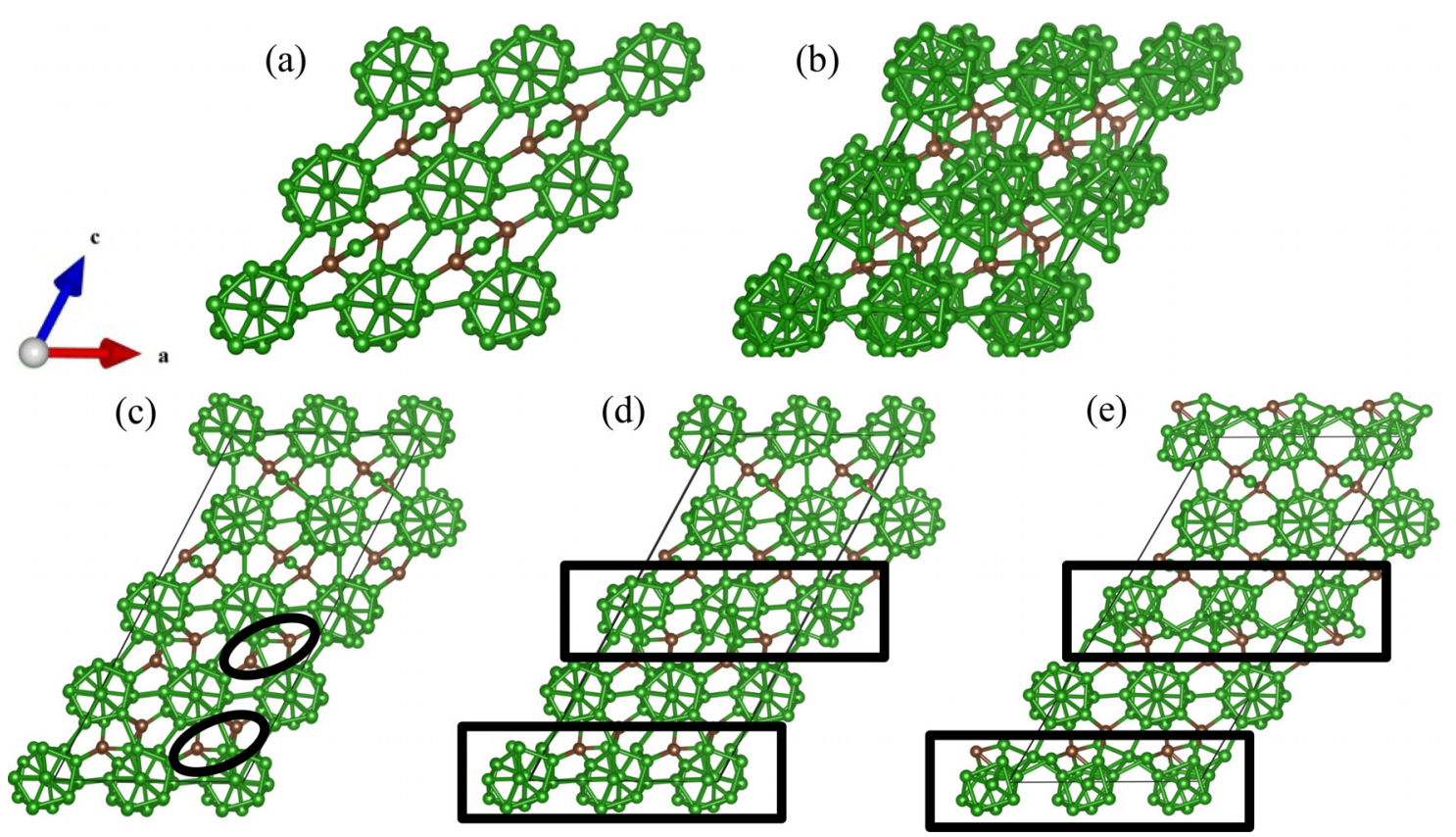

FIG. 3. The deformation mechanism of $B_{12}(C B C)$ and twinned $B_{12}(C B C)$ for shear along the least shear slip system: (a) The $B_{12}(C B C)$ structure at 0.331 strain corresponding to the maximum shear stress of $45.8 \mathrm{GPa}$. (b) The $\mathrm{B}_{12}(\mathrm{CBC})$ structure at 0.348 strain after failure. (c) The $\mathrm{B}_{12}(\mathrm{CBC})$ twinned structure at 0.299 strain, which corresponds to the maximum shear stress of $35.9 \mathrm{GPa}$. (d) The $\mathrm{B}_{12}(\mathrm{CBC})$ twinned structure at 0.322 strain corresponding to slight damage on the icosahedral clusters along the TBs. (e) The $\mathrm{B}_{12}(\mathrm{CBC})$ twinned structure at 0.392 strain with fully deconstruction of icosahedral clusters along the TBs.

oval region of Fig. 3(c). As the strain increases to 0.299, The C-B-C angle bends to $165.3^{\circ}$ and the middle $\mathrm{B}$ is $1.93 \AA$ from the cage $\mathrm{B}$. With further shear to 0.322 strain (Fig. $3(\mathrm{~d}))$, the middle chain boron is only $1.75 \AA$ from the cage $\mathrm{B}$, leading to $\mathrm{B}-\mathrm{B}$ bond formation that deconstructs partially the icosahedron (rectangular region of Fig. 3(d)), and leading to shear stress release from $35.9 \mathrm{GPa}$ to $30.8 \mathrm{GPa}$. With further shear to 0.392 strain, the cages along the TBs and the nearby chains become fully deconstructed with the shear stress decreasing to $15.3 \mathrm{GPa}$, as shown in the rectangular region of Fig. 3(e).

The stress conditions under indentation experiments are very complex compared with our simulated pure shear deformation. To predict the material behavior under indentation experiments, we performed biaxial shear deformation to mimic the stress conditions under indentation. ${ }^{26}$ The stressstrain relationships for the perfect and twinned $\mathrm{B}_{12}(\mathrm{CBC})$ are shown in Fig. 4(a). For perfect $\mathrm{B}_{12}(\mathrm{CBC})$, the maximum shear stress is $28.6 \mathrm{GPa}$, which is only slightly higher than that of the $\mathrm{B}_{11} \mathrm{C}_{\mathrm{p}}(\mathrm{CBC})(28.5 \mathrm{GPa})$. This indicates that the hardness of perfect $B_{12}(C B C)$ should be close to $B_{11} C_{p}(C B C)$. However, for twinned $\mathrm{B}_{12}(\mathrm{CBC})$, the maximum shear stress decreases to $26.0 \mathrm{GPa}$, which is $9.1 \%$ lower than perfect $\mathrm{B}_{12}(\mathrm{CBC})$ and $8.8 \%$ lower than $\mathrm{B}_{11} \mathrm{C}_{\mathrm{p}}(\mathrm{CBC})$. The critical shear stress under biaxial shear deformation is summarized in Table I.

The mechanism of deformation for twinned $\mathrm{B}_{12}(\mathrm{CBC})$ under biaxial shear deformation is displayed in Figs. 4(b) and 4(c). As a compressive stress is applied, the C-B-C chains bend by $50.3^{\circ}$ over the whole simulation cell. As the shear strain increases to 0.276 , the C-B-C chains next to the TBs bend from $180^{\circ}$ to $129.7^{\circ}$. As the shear strain increases to 0.299 , the C-B$\mathrm{C}$ chain bends to $124.5^{\circ}$, decreasing the distance from the $\mathrm{B}$ of the $\mathrm{C}-\mathrm{B}-\mathrm{C}$ chain to the $\mathrm{B}$ of the icosahedron to $1.64 \AA$, This leads to the failure of the cluster along the TBs, which is similar to the process under pure shear deformation.
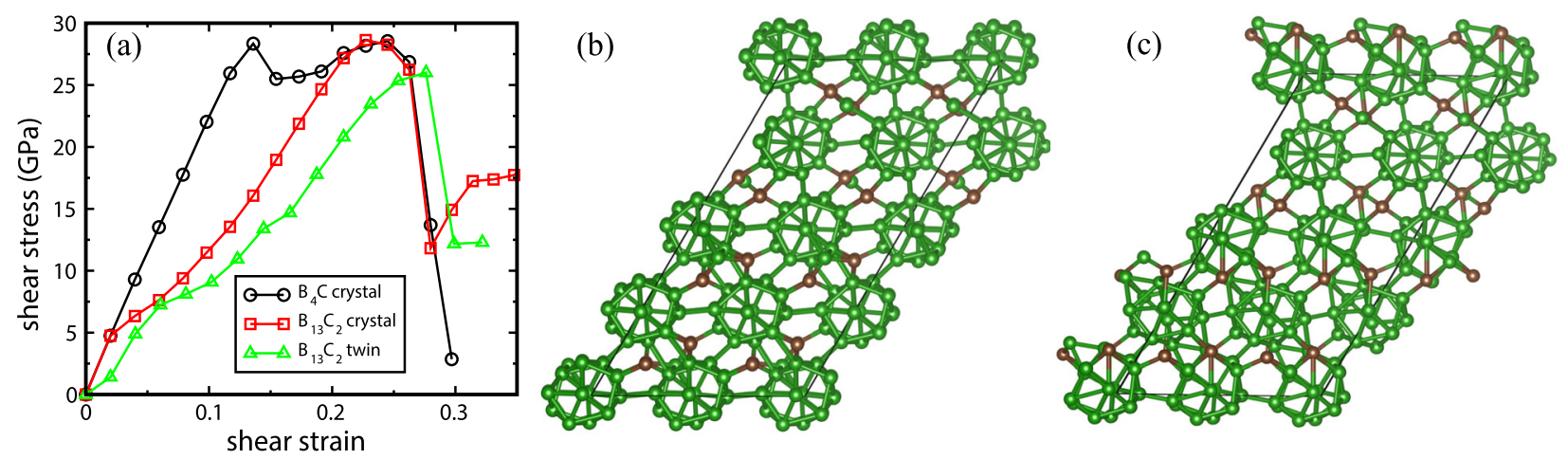

FIG. 4. The stress-strain relationships of $\mathrm{B}_{12}(\mathrm{CBC})$, twinned $\mathrm{B}_{12}(\mathrm{CBC})$, and $\mathrm{B}_{4} \mathrm{C}$ under biaxial shear deformation and the structural changes for twinned $\mathrm{B}_{12}(\mathrm{CBC})$ : (a) Stress-strain relationships; (b) twinned $\mathrm{B}_{12}(\mathrm{CBC})$ structure at 0.276 strain corresponding to the maximum shear stress of $26.0 \mathrm{GPa}$; (c) twinned $\mathrm{B}_{12}(\mathrm{CBC})$ structure at 0.299 strain after failure. 
Our previous study ${ }^{15}$ showed that nanotwins in $\mathrm{B}_{11} \mathrm{C}_{\mathrm{p}}(\mathrm{CBC})$ increase the strength compared to the perfect $\mathrm{B}_{11} \mathrm{C}_{\mathrm{p}}(\mathrm{CBC})$ because the presence of twins suppresses the stress decrease as the $\mathrm{B}-\mathrm{C}$ bond between icosahedral clusters breaks. However, the nanotwins in $\mathrm{B}_{12}(\mathrm{CBC})$ decrease the strength of the perfect crystal because the failure mechanism of $\mathrm{B}_{12}(\mathrm{CBC})$ does not involve the $\mathrm{B}-\mathrm{C}$ bond breaking between icosahedra. The high interfacial energy of the twin makes the interaction of $\mathrm{C}-\mathrm{B}-\mathrm{C}$ chain with icosahedra easier to proceed in the twinned $\mathrm{B}_{12}(\mathrm{CBC})$. Thus, although $B_{12}(C B C)$ has a very similar twin structure to $B_{11} C_{p}(C B C)$, the twins play quite different roles in these two materials due to the difference in the failure mechanisms. To improve the strength of $\mathrm{B}_{12}(\mathrm{CBC})$, one needs to design this material to have lower twin densities, which is opposite to $\mathrm{B}_{11} \mathrm{C}_{\mathrm{p}}(\mathrm{CBC})$.

Niihara et al. reported that, for chemical vapor deposited (CVD) boron carbide, both hardness and fracture toughness decreases over $18.0 \%$ as the boron content increases. ${ }^{27}$ However, mechanical test on hot-pressed boron carbide indicated that boron addition did not significantly affect elastic modulus, flexural strength, hardness, and fracture toughness. ${ }^{28,29}$ The latter two experiments on hot processed boron carbide are consistent with our theoretical prediction that the critical failure stress for $\mathrm{B}_{13} \mathrm{C}_{2}$ and $\mathrm{B}_{4} \mathrm{C}$ are similar (changes $<1.0 \%$ ) under biaxial shear deformation.

In summary, we use QM simulations to examine deformations of both twinned and nontwinned $\mathrm{B}_{12}(\mathrm{CBC})$ under both pure shear and biaxial shear conditions, which we compare with deformation of both perfect $\mathrm{B}_{11} \mathrm{C}_{\mathrm{p}}(\mathrm{CBC})$ and its twin. Some main conclusions are as follows:

- The twin interfacial energy of $\mathrm{B}_{12}(\mathrm{CBC})$ is $40.6 \mathrm{~mJ} / \mathrm{m}^{2}$, which is $\sim 1 / 2$ value for symmetric twins in $\mathrm{B}_{11} \mathrm{C}_{\mathrm{p}}(\mathrm{CBC})$.

- Perfect $\mathrm{B}_{12}(\mathrm{CBC})$ has a higher shear strength than $\mathrm{B}_{11} \mathrm{C}_{\mathrm{p}}(\mathrm{CBC})$ under pure shear conditions. The reason is that the presence of twins in $\mathrm{B}_{12}(\mathrm{CBC})$ lowers the shear strength, making it softer than $\mathrm{B}_{11} \mathrm{C}_{\mathrm{p}}(\mathrm{CBC})$. The failure mechanism for twinned $\mathrm{B}_{12}(\mathrm{CBC})$ involves the interaction of the C-B-C chain with the icosahedra along the TBs.

- Under biaxial shear conditions, perfect $\mathrm{B}_{12}(\mathrm{CBC})$ has a shear strength similar to $\mathrm{B}_{11} \mathrm{C}_{\mathrm{p}}(\mathrm{CBC})$. But twinned $\mathrm{B}_{12}(\mathrm{CBC})$ has a lower shear strength than perfect $\mathrm{B}_{12}(\mathrm{CBC})$ or $\mathrm{B}_{11} \mathrm{C}_{\mathrm{p}}(\mathrm{CBC})$. The failure mechanism of twinned $\mathrm{B}_{12}(\mathrm{CBC})$ under biaxial shear deformation is similar to the mechanism under pure shear deformation.
This work was supported by the Defense Advanced Research Projects Agency (W31P4Q-13-1-0010 and W31P4Q1210008, program manager, John Paschkewitz), by the Army Research Laboratory under Cooperative Agreement Number W911NF-12-2-0022, and by the National Science Foundation (DMR-1436985, program manager, John Schlueter). Q.A. was also supported by the U.S. Nuclear Regulatory Commission (NRC-HQ-84-15-G-0028).

The authors declare no competing financial interests.

${ }^{1}$ F. Thevenot, J. Eur. Ceram. Soc. 6, 205 (1990).

${ }^{2}$ V. Domnich, S. Reynaud, R. A. Haber, and M. Chhowalla, J. Am. Ceram. Soc. 94, 3605 (2011).

${ }^{3}$ J. L. Hoard and R. E. Hughes, The Chemistry of Boron and Its Compounds (Wiley, New York, 1967).

${ }^{4}$ A. K. Suri, C. Subramanian, J. K. Sonber, and T. Murthy, Int. Mater. Rev. 55, 4 (2010).

${ }^{5}$ N. K. Bourne, Proc. R. Soc. London, Ser. A 458, 1999 (2002).

${ }^{6}$ M. W. Chen, J. W. McCauley, and K. J. Hemker, Science 299, 1563 (2003).

${ }^{7}$ K. M. Reddy, P. Liu, A. Hirata, T. Fujita, and M. W. Chen, Nat. Commun. 4, 2483 (2013).

${ }^{8}$ Q. An, W. A. Goddard III, and T. Cheng, Phys. Rev. Lett. 113, 095501 (2014).

${ }^{9}$ Q. An and W. A. Goddard III, Phys. Rev. Lett. 115, 105501 (2015).

${ }^{10}$ Q. Yu, Z.-W. Shan, J. Li, X.-X. Huang, L. Xiao, J. Sun, and E. Ma, Nature 463, 335 (2010).

${ }^{11}$ M. Meyers, A. Mishra, and D. J. Benson, Prog. Mater. Sci. 51, 427 (2006).

${ }^{12}$ Q. An, K. M. Reddy, J. Qian, K. J. Hemker, M.-W. Chen, and W. A. Goddard III, Nat. Comm. 7, 11001 (2016).

${ }^{13}$ Q. An, K. M. Reddy, H.-F. Dong, M.-W. Chen, A. R. Oganov, and W. A. Goddard III, Nano Lett. 16, 4236 (2016).

${ }^{14}$ K. Xie, Q. An, M. F. Toksoy, J. W. McCauley, R. A. Haber, W. A. Goddard III, and K. J. Hemker, Phys. Rev. Lett. 115, 175501 (2015).

${ }^{15}$ Q. An, W. A. Goddard III, K. Xie, G.-D. Sim, K. J. Hemker, T. Munhollon, M. F. Toksoy, and R. A. Haber, Nano. Lett. 16(12), 7573 (2016).

${ }^{16}$ G. H. Kwei and B. Morosin, J. Phys. Chem. 100(19), 8031 (1996).

${ }^{17}$ D. E. Taylor, J. W. McCauley, and T. Wright, J. Phys.: Condens. Matter. 24(50), 505402 (2012).

${ }^{18}$ T. L. Aselage and R. G. Tissot, J. Am. Ceram. Soc. 75(8), 2207 (1992).

${ }^{19}$ M. Calandra, N. Vast, and F. Mauri, Phys. Rev. B 69(22), 224505 (2004).

${ }^{20}$ K. Shirai and S. Emura, J. Phys. Condens. Matter. 8, 10919 (1996).

${ }^{21}$ G. Kresse, Phys. Rev. B. 47, 558 (1993).

${ }^{22}$ G. Kresse and J. Furthmüller, Comput. Mater. Sci. 6, 15 (1996).

${ }^{23}$ G. Kresse and J. Furthmüller, Phys. Rev. B 54, 11169 (1996).

${ }^{24}$ G. Kresse and D. Joubert, Phys. Rev. B 59, 1758 (1999).

${ }^{25}$ D. Roundy, C. R. Krenn, M. L. Cohen, and J. W. Morris, Jr., Phys. Rev. Lett. 82, 2713 (1999).

${ }^{26}$ B. Li, H. Sun, and C.-F. Chen, Nat. Commun. 5, 4965 (2014).

${ }^{27}$ K. Niihara, A. Nakahira, and T. Hirai, J. Am. Ceram. Soc. 67, C13 (1984).

${ }^{28}$ B. Champagne and R. Angers, J. Am. Ceram. Soc. 62, 149 (1979).

${ }^{29}$ P. Larsson, N. Axén, and S. Hogmark, J. Mater. Sci. 35, 3433 (2000). 